\title{
AVALIAÇÃO ANTAGONISTA DE BACTÉRIAS ÁCIDO LÁTICAS ISOLADAS DE QUEIJO DE COALHO ARTESANAL PRODUTORAS DE BACTERIOCINAS
}

\author{
E. F. COSTA. ${ }^{1}$; M. S. F. LIMA. ${ }^{1,2}$; A. L. F. PORTO. ${ }^{1,2}$; M. T. H. CAVALCANTI ${ }^{1,2}$ \\ ${ }^{1}$ Universidade Federal Rural de Pernambuco, Centro de Apoio à Pesquisa \\ ${ }^{2}$ Universidade Federal Rural de Pernambuco, Departamento de Morfologia e Fisiologia \\ Animal \\ E-mail para contato: mtcvsoares@yahoo.com.br
}

\begin{abstract}
RESUMO - Bactérias ácido láticas (BAL) ocorrem naturalmente em alimentos fermentados como o queijo de Coalho e suas bacteriocinas podem ser aceitas como aditivos alimentares pelas autoridades de saúde e pelos consumidores. Assim, a busca por bacteriocinas de BAL consideradas seguras é importante. O objetivo deste estudo foi avaliar o antagonismo de $30 \mathrm{BAL}$ isoladas de queijos de Coalho artesanais do Estado de Pernambuco. A atividade antagonista foi realizada com as cepas indicadoras Enterococcus faecalis, Listeria innocua e Bacillus cereus. Dentre as BAL testadas, 36,66\%; 46,66\% e 10\% apresentaram atividade antagonista frente a três, duas e uma cepa indicadora, respectivamente. Entre as BAL que apresentaram atividade antagonista neste trabalho, 40\% inibiram o crescimento de Listeria innocua, 89\% foram eficientes para Enterococcus faecalis e $100 \%$ inibiram o crescimento do Bacillus cereus. Neste trabalho encontramos BAL produtoras de bacteriocinas que poderão ser aplicadas na preservação de alimentos, reduzindo o uso de conservantes químicos, resultando em produtos naturalmente preservados e ricos em propriedades organolépticas e nutricionais.
\end{abstract}

\section{INTRODUÇÃO}

O queijo de Coalho é um alimento típico brasileiro que é produzido com leite cru ou pasteurizado na Região Nordeste há mais de 150 anos. Este produto possui um elevado valor comercial, tecnologia de fabricação simples, alto rendimento e boa aceitação pelos consumidores. É um queijo classificado como de alta umidade, obtido após a coagulação do leite com a quimosina, às vezes complementado com bactérias ácido láticas (BAL) 
selecionadas e comumente vendido até o sétimo dia de armazenamento a $10^{\circ} \mathrm{C}$ (Queiroga et al., 2013).

A microbiota natural dos produtos lácteos desempenha funções importantes no desenvolvimento de características sensoriais e na manutenção da saúde do homem. A elevada capacidade das BAL em transformar substratos por vias metabólicas específicas, inicialmente usadas como incremento na fermentação de alimentos, também utilizada na produção industrial de biopolímeros, enzimas, etanol e ácido láctico. Essa microbiota tem sido amplamente estudada, quer seja pela busca por culturas láticas adequadas para a fabricação de determinado produto, quer seja por propriedades específicas como atividade probiótica ou a produção de bacteriocinas (Randazzo et al., 2009).

Bacteriocinas são peptídeos ou proteínas antimicrobianas sintetizadas nos ribossomos das células bacterianas e liberadas no meio extracelular que apresentam ação bactericida ou bacteriostática sobre microrganismos taxonomicamente relacionados. Além disso, não promovem alteração na qualidade sensorial do produto, observando-se o crescente interesse da indústria de alimentos sobre o potencial de utilização destes compostos em substituição aos conservantes químicos (Oliveira et al., 2012).

Pesquisas com bacteriocinas de bactérias láticas têm-se expandido nos últimos anos. Suas propriedades antagonistas sobre outros microrganismos aliadas à história de seu uso em produtos fermentados tradicionais, as tornam muito atrativas para serem utilizadas como bioconservantes. Como as bactérias láticas ocorrem naturalmente em muitos alimentos fermentados, suas bacteriocinas podem ser mais facilmente aceitas como aditivos alimentares pelas autoridades de saúde e pelos consumidores. Uma vez que a adição de antibióticos não é permitida em alimentos, as bacteriocinas tornam-se um interessante grupo de biomoléculas com propriedades microbianas que surgem como uma boa alternativa. $\mathrm{O}$ interesse por esses compostos tem estimulado o isolamento e a caracterização de peptídeos antimicrobianos produzidos por bactérias láticas (Oliveira et al., 2012).

A busca por bacteriocinas de BAL consideradas seguras é importante. O objetivo do presente estudo foi avaliar o antagonismo de 30 BAL dos gêneros Lactobacillus, Enterococcus e Streptococcus isolados de queijos de Coalho artesanais do Estado de Pernambuco-BR.

\section{MATERIAL E MÉTODOS}

\subsection{Amostras}

A pesquisa foi realizada no laboratório de Tecnologia Agroindustrial localizado no Centro de Apoio a Pesquisa (CENAPESQ) da Universidade Federal Rural de Pernambuco (UFRPE). 
Aproximadamente 200 amostras fazem parte do acervo de bactérias ácido láticas pertencente ao nosso laboratório. Todas elas foram isoladas de queijos de Coalho artesanais produzidos na Região Agreste e 30 foram escolhidas de forma aleatória.

Os gêneros das BAL foram previamente identificados, as bactérias que apresentaram morfologia de cocos (Lactococcus, Leuconostoc, Streptococcus, Enterococcus), foram submetidas aos testes de crescimento em caldo APT (Himedia, Índia) nas seguintes condições: temperatura de 10 e $45^{\circ} \mathrm{C}, \mathrm{pH}$ de 4,4, e 9,6; teor de $\mathrm{NaCl} 6,5 \%$; e produção de $\mathrm{CO}_{2}$ a partir da glicose (Harrigan, 1998). Para uma confirmação do gênero Streptococcus, foi realizado um teste adicional com crescimento a $60^{\circ} \mathrm{C}$. As BAL em formato de bastão (Lactobacillus) foram submetidas aos testes de crescimento em caldo APT (Himedia, Índia) a temperaturas de 10 e $45^{\circ} \mathrm{C}$, incubadas respectivamente por 5 e 2 dias, testes de crescimento a pH de 4,4, e 9,6 e produção de $\mathrm{CO}_{2}$ (Cogan et al., 1997).

\subsection{Reativação das bactérias ácido-lácticas}

As culturas selecionadas foram descongeladas a temperatura ambiente e reativadas duas vezes em meio LDR (leite desnatado reconstituído) a 12\%, e incubadas de acordo com a temperatura de isolamento a $30^{\circ} \mathrm{C}$ ou $37^{\circ} \mathrm{C}$ por 48 horas.

\subsection{Antagonismo in vitro contra cepas patogênicas}

O efeito antagônico foi realizado de acordo com Tagg et al. (1976), com a utilização do caldo MRS (Himedia, Índia) para o cultivo das bactérias ácido láticas e incubação a $30^{\circ} \mathrm{C}$ e $37^{\circ} \mathrm{C}$, por 24 horas. As cepas de patógenos de referência utilizadas como reveladoras Enterococcus faecalis (ATCC 6057), Listeria innocua (ATCC 33090), Bacillus cereus (ATCC 33018), foram crescidas em caldo BHI (Himedia, Índia) a $37^{\circ} \mathrm{C}$, durante 24 horas, em aerobiose.

Após o crescimento das BAL $5 \mu \mathrm{L}$ de cada cultivo foram colocados sobre um disco de papel disposto na superfície de uma placa de Petri contendo Ágar MRS e incubados sob aerobiose a $37^{\circ} \mathrm{C}$ e $30^{\circ} \mathrm{C}$ durante 24 horas em duplicata. Após $18-24 \mathrm{~h}$ foram colocados $10 \mathrm{~mL}$ de Ágar BHI contendo as cepas reveladoras na concentração de $10^{6} \mathrm{UFC} / \mathrm{mL}$ de acordo com a escala de MacFarland, foram incubadas a $37^{\circ} \mathrm{C}$ durante 24 horas, em aerobiose. A simples presença de um halo de inibição, independente do diâmetro, é indicativa do antagonismo.

\section{RESULTADOS E DISCUSSÕES}

\subsection{Antagonismo in vitro contra cepas patogênicas}


Dentre as bactérias que mostraram atividade, 11 BAL $(36,66 \%)$ exibiram atividade antagonista frente às três bactérias indicadoras testadas (Enterococcus faecalis, Bacillus cereus, Listeria innocua); 3 cepas (10\%) inibiram pelo menos uma bactéria indicadora; 14 BAL $(46,66 \%)$ apresentaram atividade inibitória contra duas das bactérias indicadoras e 2 cepas $(6,66 \%)$ dos gêneros Enterococcus e Lactobacilus não apresentaram antagonismo em relação a nenhuma cepa patogênica. Estes resultados estão expressos na Figura 1.

\section{Percentagem de BAL}

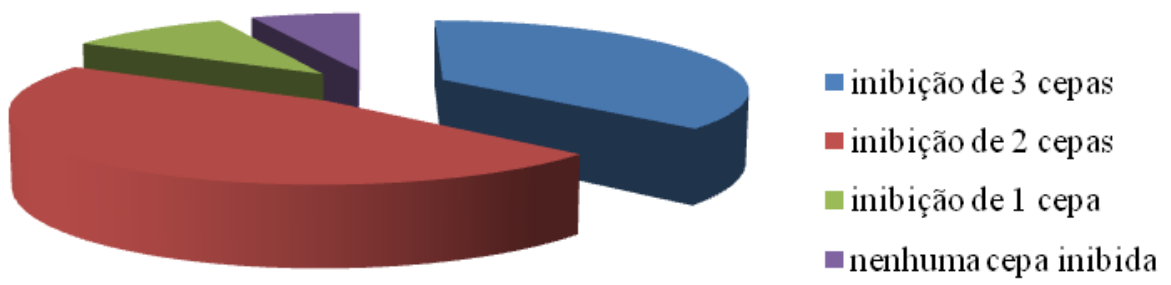

Figura 1 - Resultado da avaliação antagonista de bactérias ácido-láticas isoladas de queijos de Coalho artesanais produzidos na região Agreste de Pernambuco.

Todas as BAL testadas com atividade antagonista (2 Lactobacillus, 20 Enterococcus e 6 Streptococcus) inibiram o crescimento de Bacillus cereus, destas 24 inibiram o crescimento de Enterococcus faecalis e 12 inibiram o crescimentos da Listeria innocua (Figura 2).

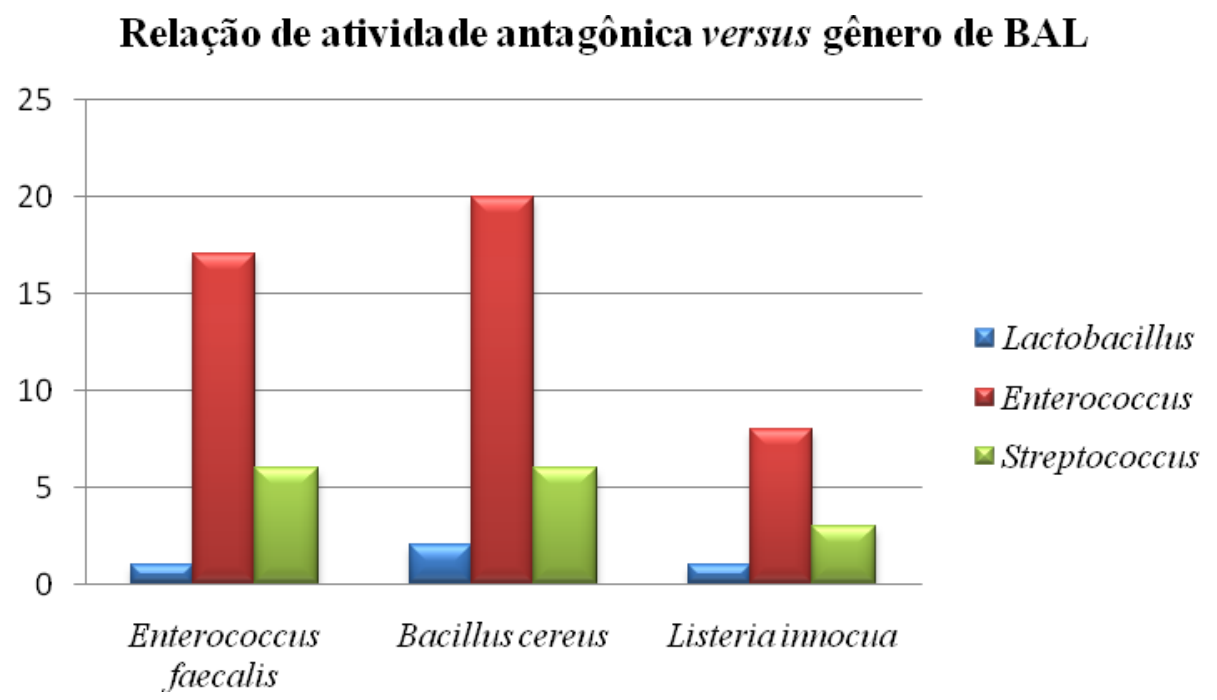

Figura 2 - Relação da atividade antagonista dos gêneros de BAL com as cepas indicadoras. 
Resultados semelhantes aos deste trabalho foram encontrados por outros autores que também demonstraram atividade antagonista de bactérias ácido láticas isoladas de queijo artesanal frente a patógenos. Coventry et al. (1997) observaram que $25 \%$ das cepas isoladas de produtos lácteos foram capazes de inibir o crescimento de Listeria sp., esses valores foram inferiores aos resultados apresentados neste trabalho, nos quais aproximadamente $40 \%$ das BAL apresentaram antagonismo contra a L. innocua.

No presente trabalho $100 \%$ e $89 \%$ das BAL que mostraram atividade antagonista frente a $B$. cereus e E. faecalis, respectivamente. A inibição do crescimento de $E$. faecalis e $B$. cereus por bactérias do queijo de Coalho é importante na inocuidade do produto, uma vez que podem produzir toxina termoestável e após a ingestão provocar sintomas como vômito e dores abdominais (Jawetz et al., 1991).

A atividade antimicrobiana direta produzida pela microbiota estudada nesta pesquisa pode ser devida a vários fatores como, por exemplo, a produção de ácidos orgânicos, peróxido de hidrogênio, diacetil, dióxido de carbono, acetaldeído e bacteriocinas (Franco et al., 2006; Fernandes et al., 2008). Também, tem influência o fato de as estirpes de bactérias láticas e o microrganismo indicador patogênico se desenvolverem ao mesmo tempo (Figura 3), proporcionando a inibição por competição pelos nutrientes presentes no meio.

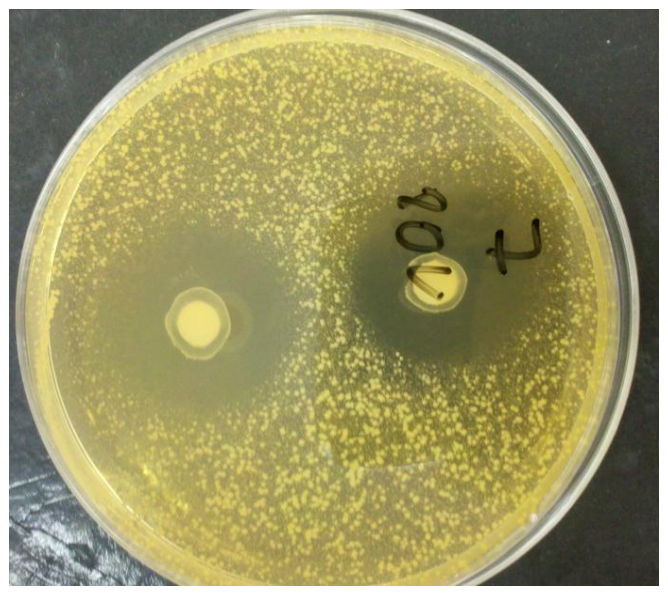

Figura 3 - Inibição de Bacillus cereus ATCC 33018 por uma cepa de Enterococcus sp.

A atividade antimicrobiana por bacteriocinas, em geral, são uma das opções em um mosaico de possíveis mecanismos para controlar bactérias patogênicas e deteriorantes em alimentos. Porém é importante lembrar que as substancias antimicrobianas dificilmente poderão substituir as boas práticas de fabricação fundamentais para produção de alimentos seguros.

\section{CONCLUSÕES}


Neste trabalho encontramos BAL produtoras de bacteriocinas que poderão ser aplicadas na preservação de alimentos, ajudando na redução de conservantes químicos, resultando em produtos naturalmente preservados e ricos em propriedades organolépticas e nutricionais. Essas observações indicam interessante perspectiva tecnológica de utilização dessas culturas de BAL para o controle de patógenos, principalmente em queijos artesanais.

\section{REFERÊNCIAS}

COGAN, T.M.; BARBOSA, M.; BEUVIER, E.; BIANCHI-SALVADORI, B.; COCCONCELLI, P.S.; FERNANDES, I.; GOMEZ, J.; GOMEZ, R.; ALANTZOUPOULOS, G. LEDDA, A.; MEDINA, M.; REA, M. C.; RODRIGUEZ, E. Characterization of the latic acid bacteria in artisanal dairy products. J. Dairy Res., v.64, p. 409-421, 1997.

COVENTRY, M.J.; GORDON, J.B.; WILCOCK, A.; HARMARK, K.; DAVIDSON, B.E.; HICKEY, M.W.; HILLIER, A.J.; WAN, J. Detection of bacteriocins of lactic acid bacteria isolated from foods and comparison with pediocin and nisin. J. Appl. Microb., v. 83, p. 248258, 1997.

FERNANDES, C.E.; BENTO, R.A.; STAMFORD, T.L.M. Probióticos: aspectos fisiológicos, terapêuticos e tecnológicos. Hig. aliment., v.22, p.16-21, 2008.

FRANCO, R.M.; OLIVEIRA, L.A.T.; CARVALHO, J.C.A.P. Probióticos - Revisão. Hig. aliment., v.20, p.22-33, 2006.

HARRIGAN, W.F. Laboratory methods in food microbiology. Academic Press: London, 1998.

JAWETZ, E.; MELNICK, J. L.; ADELBERG, E. A.; BROOKS, G. F.; BUTEL, J. S.; ORNSTON, L. N. Microbiologia Médica. Rio de Janeiro: Guanabara Koogan, 1991.

OLIVEIRA, C.P.; JÚNIOR, J.P.S.; SILVA, J.A. Bacteriocinas como alternativa na conservação de alimentos. Rev. Verde, v.7, p. 09-15, 2012.

QUEIROGA, R.C.R.E.; SANTOS, B.M.; GOMES, A.M.P.; MONTEIRO, M.J.; TEIXEIRA, S.M.; SOUZA, E.L.; PEREIRA, C.J.D.; PINTADO, M.M.E. Nutritional, textural and sensory properties of Coalho cheese made of goats', cows' milk and their mixture. LWT-Food Sci. Technol., v.50, p. 538-544, 2013.

RANDAZZO, C.L.; CAGGIA, C.; NEVIANI, E. Application of molecular approaches to study lactic acid bacteria in artisanal cheeses, Review, J. Microbiol. Meth., v. 78, p. 1-9, 2009. 
TAGG, J.R.; DAJANI, A.S.; WANNAMAKER, L.M. Bacteriocins of gram positive bacteria. Bacteriol. rev., v 40, p 722-756, 1976. 